\title{
The Low-Fertility Trap Hypothesis: Forces that May Lead to Further Postponement and Fewer Births in Europe
}

\author{
Wolfgang Lutz, Vegard Skirbekk, and Maria Rita Testa*
}

\begin{abstract}
This paper starts from the assessment that there is no good theory in the social sciences that would tell us whether fertility in low-fertility countries is likely to recover in the future, stay around its current level or continue to fall. This question is key to the discussion whether or not governments should take action aimed at influencing the fertility rate. To enhance the scholarly discussion in this field, the paper introduces a clearly defined hypothesis which describes plausible self-reinforcing mechanisms that would result, if unchecked, in a continued decrease of the number of births in the countries affected. This hypothesis has three components: a demographic one based on the negative population growth momentum, i.e., the fact that fewer potential mothers in the future will result in fewer births; a sociological one based on the assumption that ideal family size for the younger cohorts is declining as a consequence of the lower actual fertility they see in previous cohorts; and an economic one based on the first part of Easterlin's (1980) relative income hypothesis, namely, that fertility results from the combination of aspirations and expected income, and assuming that aspirations of young adults are on an increasing trajectory while the expected income for the younger cohorts declines, partly as a consequence of population ageing induced by low fertility. All three factors would work towards a downward spiral in births in the future. If there is reason to assume that such mechanisms will indeed be at work, then this should strengthen the motivation of governments to take immediate action (possibly through policies addressing the tempo effect) in order to still escape from the expected trap.
\end{abstract}

\footnotetext{
* Wolfgang Lutz (author for correspondence), Vienna Institute of Demography, Vienna, Austria and International Institute for Applied Systems Analysis, Schlossplatz 1, A-2361 Laxenburg, Austria.E-mail: lutz@iiasa.ac.at

Vegard Skirbekk, International Institute for Applied Systems Analysis, Laxenburg, Austria.

Maria Rita Testa, Vienna Institute of Demography, Austrian Academy of Sciences, Vienna, Austria.
} 


\section{Introduction}

Over the last three decades, birth rates have been on the decline in virtually all countries of the world, and it is estimated that already more than half of the world's population has below -replacement level fertility (Wilson 2004). An increasing number of countries have birth rates that are not just somewhat under replacement fertility, but far below that level. Measured in terms of the Total Fertility Rate (TFR), currently 34 countries have fertility levels of 1.5 or less (PRB 2005).

Is this low fertility here to stay? Will the birth rates recover or even continue to fall? Nobody knows! So far the social sciences have not produced a plausible theory of fertility that would have predictive power. There are not even many testable hypotheses in the field of fertility trends. In a recent paper, Lutz (2006) tries to summarise different arguments that have been put forward in the literature which suggest either higher or lower fertility in the future. He finds roughly an equal number of arguments for both directions, but there is no basis for weighting them in order to come up with an estimated net effect. Moreover, few of these arguments are precise enough to be subject to empirical testing. This is particularly the case with the rather vague arguments that suggest continued declines in fertility.

Hence, the main purpose of this paper is to present and discuss a clearlystructured and consistent hypothesis which suggests that the birth rate in Europe will continue to decline, the key premises of which can be empirically tested. The purpose for doing so is to contribute to a more rational scholarly discussion about the future of fertility which could also be an important basis for the question whether governments should intervene and try to influence the course of fertility. Presenting the logic of this hypothesis and some supporting evidence means that the authors consider this a plausible hypothesis that should get serious consideration and does not necessarily imply that the authors actually believe that-viewing all things together-fertility will continue to decline. Conclusions along this line should be based on a much broader analysis that also includes the consideration of possible counter arguments as discussed in the concluding section of the paper. Here the sole purpose is to present a plausible story in the form of a testable hypothesis together with some prima facie evidence that will motivate the research community in this field to take the hypothesis serious and start testing it under different settings and conditions.

The notion of a low-fertility trap hypothesis (LFTH) has recently been introduced by Lutz and Skirbekk (2005) in the context of a paper dealing with policies addressing the tempo effect in low-fertility countries. There the main argument was: If such a low-fertility trap exists, then the rationale for implementing policies that would give a short-term boost to period fertility levels would be strengthened. Since there was not much elaboration of the LFTH itself in that paper, we will try to present a more extensive discussion here. 
The paper will be structured as follows. After a short review of what recent international population projections assume about future fertility trends, we will present the full hypothesis and show how its different elements can work together to result in fewer births in the future. Then we will discuss separately the three elements of LFTH: the demographic, the sociological and the economic argument. We will end with a discussion about the empirical testability of the hypothesis and possible policy implications.

\section{Why do Current Population Projections Assume that Life Expectancy Continues to Increase while Fertility Stops to Decline?}

When discussing the fertility assumptions made in population projections it is interesting to compare them to the history of mortality assumptions where recently a radical departure from the traditional assumption of a near-term levelling off in life expectancy has taken place. Maybe a similar departure from the traditional assumption that the decline of fertility will come to an abrupt end would now be appropriate.

In the past decades, population projections were based on the expectation that after the end of the demographic transition, life expectancy would reach a certain maximum level and fertility would stabilise in the long run at around replacement level implying long-term convergence of all countries in terms of fertility and mortality levels. The United Nations population projections give the longest series of consistent projections for all countries in the world and serve as a model for a large number of national population projections. Until very recently, they have assumed that there is a maximum life expectancy that no country in the world will surpass. In the 1973 assessment, this maximum life expectancy was assumed to be 72.6 years for men and 77.5 years for women (Bucht 1996). As time passed, many countries came close to or even passed this assumed maximum life expectancy. As a consequence, the UN has been slowly moving the assumed maximum life expectancy upwards. In the 1982 assessment of the UN projections, the maximum age was assumed to be 75 years for men and 82.5 years for women. Only 20 years after this assumption was made, a large number of countries had again already surpassed the assumed maximum age and the trend in increasing life expectancy shows no sign of levelling off. In fact, the trend in the countries with the world's highest life expectancy at any point in time shows an almost perfectly linear trend for more than a century with no sign of levelling off (Oeppen and Vaupel 2002). As a consequence, in their most recent population projections, the UN has given up the assumption of a maximum life expectancy and assumes continuing improvements, although at a decelerating speed (UN 2004). Most other statistical agencies now also assume a continued increase in life expectancy. 
But what about the future trend in fertility? In 1998, with a rapidly increasing number of countries falling much below the previously assumed magic target level of 2.1 children per woman, the UN (1999) abandoned their previous assumption that all countries of the world would converge to 2.1 and that no country that was still above 2.1 would ever fall below 2.1. This magic number is now assumed to be 1.85 instead of the earlier 2.10. As a consequence all countries that now have already very low fertility (1.3 or below) are assumed to recover rather quickly to 1.85; countries that are still above 1.85 are assumed to never fall below that level. Eurostat (2005), in its most recent round of national population projections for all $25 \mathrm{EU}$ member countries, makes significantly lower fertility assumptions than the UN in its medium scenario. Eurostat makes its assumptions in terms of cohort fertility, which is a much more stable indicator, and basically assumes that cohort fertility will not decline any further but rather will stabilise at its current level. In many cases this implies a moderate, near-term increase in period fertility, but to much lower levels than assumed by the UN medium variant.

Figure 1 shows the trends in cohort fertility for six selected European countries: Portugal and Spain for southern Europe, the Netherlands and Sweden for northern Europe and Austria and the Czech Republic for central Europe. It gives the completed cohort fertility for the birth cohorts since 1935 based on observed age-specific data up to 2005 , followed by the assumed fertility rates according to the Eurostat (2005) population projections. Up to the birth cohort of 1960, the data are almost entirely empirical; thereafter they are a mixture of empirical data for the younger ages and assumed fertility rates for the older ones; from the cohort of 1990 onwards, they are entirely assumed data according to Eurostat projections.

The empirical data for Spain, Italy and the Netherlands show an almost monotonous, steep decline in cohort fertility from the cohorts born in 1935 to those born in 1975. For these 40 years, each successive cohort had a lower completed fertility than the previous one. The fertility trends assumed by Eurostat imply an abrupt end of this pervasive trend for the cohorts born after 1975. The Eurostat assumptions imply that fertility increases back up to the level of the cohorts born in the mid-1960s for Spain, Italy and the Netherlands. For Austria and the Czech Republic, the assumptions predict that the decline in cohort fertility ends and reaches a stable level of 1.45 children.

The cohort trend was less linear in Sweden. The birth cohorts of 1945 to 1960 saw a moderate increase in completed fertility levels which then was followed by a steep and almost linear decline parallel to those in Spain and Italy. But since cohort fertility in Sweden is currently still at a significantly higher level than in the two other countries, Eurostat, according to its philosophy of constant cohort fertility, assumes levels for the future that are not so different from the 1.85 that the UN assumes for all countries in the world. Hence, for Sweden, the UN and the Eurostat assumptions turn out to be similar. For all countries the Eurostat as well 
as the UN projections imply an abrupt discontinuity in the observed trend of declining cohort fertility.

\section{Figure 1:}

Trends in completed cohort fertility (empirical and as assumed by Eurostat projections) for Italy, Spain, Austria, the Czech Republic, the Netherlands and Sweden

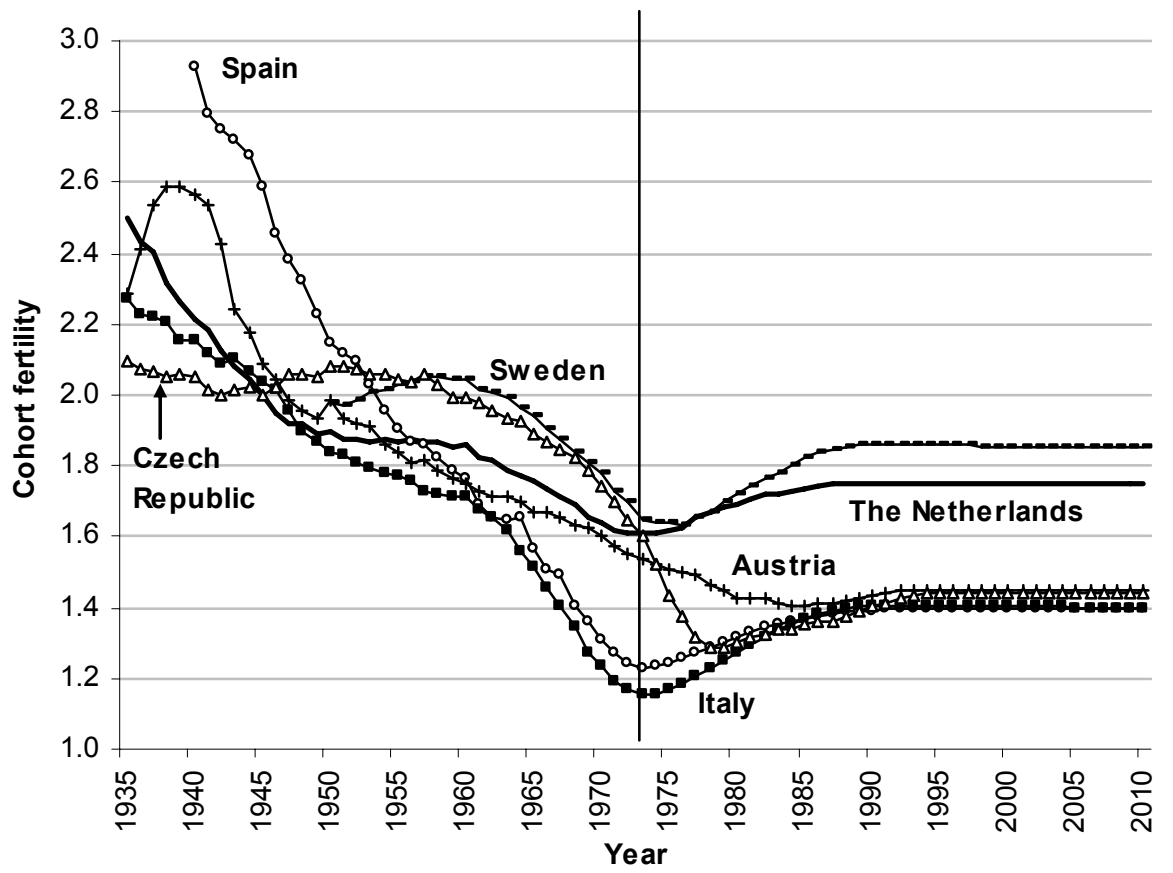

Sources: Eurostat and National Statistical Bureaus. Data on fertility rates up to 2004 were provided by Tomáš Sobotka.

Note: The vertical line indicates that the cohort fertility is predominantly projected

For what reasons do these projections assume such an unusual reversal in the trend? Typically in trend analysis, one would need to come up with a very strong and convincing reason to justify such a deviation from the pervasive trend of the past 50 years of cohort experience. Even more surprisingly, not even the lowfertility scenarios produced by these statistical agencies assume a continuation of the trend of the past decades. The low variants just assume a levelling off at a somewhat lower level. Furthermore, none of these population projections provide the users with a clear theoretical reasoning for why, in the case of fertility, the declining trend is assumed to reverse, while in the case of mortality, it is assumed to continue. When looking at the assumed drivers of mortality decline, ranging from lifestyle factors to medical progress, there are indeed good reasons to assume that likely improvements in these fields will result in further mortality declines. But the same seems to be true for the generally assumed drivers of the 
fertility decline of the past decades, ranging from the transformation of traditional family patterns to more female education, continuing secularisation and increasing uncertainty about the future resulting from rapid social change and globalisation. There is no reason to assume a reversal in the trends of many of these determinants of fertility decline in the near future. But why then do projections assume a reversal in the trend of the outcome, i.e., fertility?

This deviation from the conventional rules of trend analysis must have to do with strong beliefs that somehow there is a powerful force that will stop and even reverse the trend, i.e., that at the individual level, people will always want children, and that at the aggregate level, human populations would not voluntarily shrink and age to an extent that would be socially disruptive or in the very long run might even mean shrinking to insignificance. From an evolutionary perspective, these are seemingly reasonable assumptions because a species without a drive to reproduce would not have survived to this day. But there is a strong counterargument, namely, that through the introduction of modern contraception, the evolutionary link between the sex drive and procreation has been broken and now reproduction is merely a function of individual preferences and culturally determined norms. Since social norms can change and in related fields, such as the role of women in society, have indeed shown fundamental changes over the recent history, it cannot be ruled out that the social norms about the desire to have children will see similar, fundamental changes over the coming decades. Since such norms tend to change very slowly and the widespread use of modern contraception is only a rather recent phenomenon in Europe, the current, still apparent desire for children (although already on the decline in some countries) may simply reflect a cultural lag. This lag could be similar in nature to the well-studied lag in desired family size in the process of demographic transition, in which high fertility desires can persist several decades after infant and child mortality have declined.

Whether after the break of the evolutionary link between sex and fertility the future of reproduction is entirely a function of potentially instable, individual preferences and social norms, or whether there are other aspects of human nature, such as a caring reflex (at least among women), that may ensure the persistence of a certain desired family size, is a question that requires much further research. Here it is sufficient to conclude that there does not seem to be any "natural law" that would stop fertility from falling further, should preferences and norms change accordingly. 


\section{Three Mechanisms that May Cause a Downward Spiral in Future Birth Rates}

Our thinking about the possibility of a low-fertility trap was triggered by the recent observation of Peter McDonald (2005), who said that there tend to be two distinct groups of low-fertility countries: those where the TFR has stayed above 1.5 and those where it has fallen below the supposedly critical level and stayed below ever since. McDonald also points at the fact that in a recent UN survey about population policy, all countries with TFRs of 1.5 or below say that they consider their fertility level as too low. McDonald hypothesises that it is more difficult for a country to bring fertility up to, say, 1.6 once it has already fallen to levels of 1.3 or 1.4 than to keep fertility above 1.5. From this assumption he derives the recommendation to governments that they should make efforts to keep fertility above this critical level and let not fall it below.

Whether or not one assumes that there is a specific critical watershed level around a TFR of 1.5-we do not want to make this specific point in our paperthe underlying thinking of a non-linear dose-response relationship between government efforts and the response of fertility is a welcome contribution to broadening our thinking about the relationship between potential drivers of fertility and actual fertility change. Because linear regressions have become such a popular analytical tool, we are used to thinking that a unit change in the driver always results in a certain change of fertility, no matter at what level of fertility and under what side conditions this happens. But there are likely to be all kinds of non-linearities and possible feedback loops that may result in a bifurcation process. This may include what sociologists call a change in the demographic regime. For fertility this may imply that once fertility has fallen below certain levels and stayed there for a certain time, it might be very difficult, if not impossible, to reverse such a regime change. Recent work by Rindfuss et al. (2004) on social transitions in Japan supports this assumption of non-linear, selfreinforcing processes in social change with thresholds and tipping points.

Is it justified to call this possible mechanism of irreversible (or hardly reversible) regime change a "trap," a notion that neither McDonald nor Rindfuss use? If a trap is defined as an unpleasant situation (governments would rather see higher fertility) into which one enters unintentionally and which it is very difficult to get out of, then indeed the described demographic regime change may be called a trap. But in addition to postulating the possibility of such a tipping point in fertility, it would be good to be able to identify and describe the possible mechanisms that would constitute such a self-reinforcing process toward lower birth rates, and consequently accelerate the ageing and shrinking that are difficult to escape. In the following we will describe three such mechanisms: a demographic one, one related to social norms and an economic one.

The LFTH as presented here consists of these three independent elements that all work in the same direction and can reinforce each other. While the first is a 
demographic accounting truism, the two others are testable sub-hypotheses. One may classify the three mechanisms as demographic, sociological, and economic. To better distinguish between these three independent forces, we call them LFT-1 to LFT-3. In this section we will give a short overview and show in a schematic chart how they independently influence the birth rate. In the following sections we will then discuss LFT-2 and LFT-3 individually, because they are not yet as well understood as LFT-1.

On the left-hand side of Chart 1 we see the different measures of fertility. Since the various assumed mechanisms influence these different aspects of fertility in different ways, it is important to clearly distinguish between them. At the bottom we have the end result of this chain of influences, which is the absolute number of births in a population. This is what matters for population growth and for the change in the age structure; therefore, it is seen as the final explanandum in our analysis. If populations of different sizes shall be compared, then the absolute number of births can be replaced by the crude birth rate, which is an equivalent measure, the only difference being that it is standardised by the total population size. The absolute number of births is, in turn, a direct function of the age pattern of period fertility and the age structure of the population. Period fertility, in turn, results from a combination of cohort fertility and shifts in the timing of fertility, which can have different determinants. Finally, we assume that the level of cohort fertility is influenced by, for instance, norms indicating the ideal personal family size. These norms are also subject to changes as will be described. In studies about the determinants of birth rates, it is not yet common to clearly distinguish between these four different levels of measuring reproduction. If it were to be used more consistently, it could help avoid unnecessary confusion.

As described in Chart 1, LFT-1 operates at the level of population dynamics and refers to what demographers sometimes call the negative momentum of population growth. It is based on the well-known demographic mechanism that the age distribution of a population exerts an independent influence on the number of births or the crude birth rate, which is not a function of the fertility level of that period but results from past fertility, mortality and migration. This momentum can be a force towards shrinking in the case of a history of very low fertility that has modified the population age structure to such an extent that fewer and fewer women will enter reproductive age and, hence, the number of births will decline, even in the hypothetical case that fertility instantly jumped to replacement level. This process in itself causes a downward spiral in the number of births. If there are fewer births today, there will be fewer potential mothers down the road, which in turn will bring the number of births further down.

This purely demographic mechanism (LFT-1) is shown in the lower left corner in Chart 1. It shows the absolute number of births in a given year as a function of the level of period fertility and the age structure of the population. 


\section{Chart 1:}

The demographic (LFT-1), sociological (LFT-2) and economic (LFT-3) mechanisms that constitute the Low-Fertility Trap Hypothesis

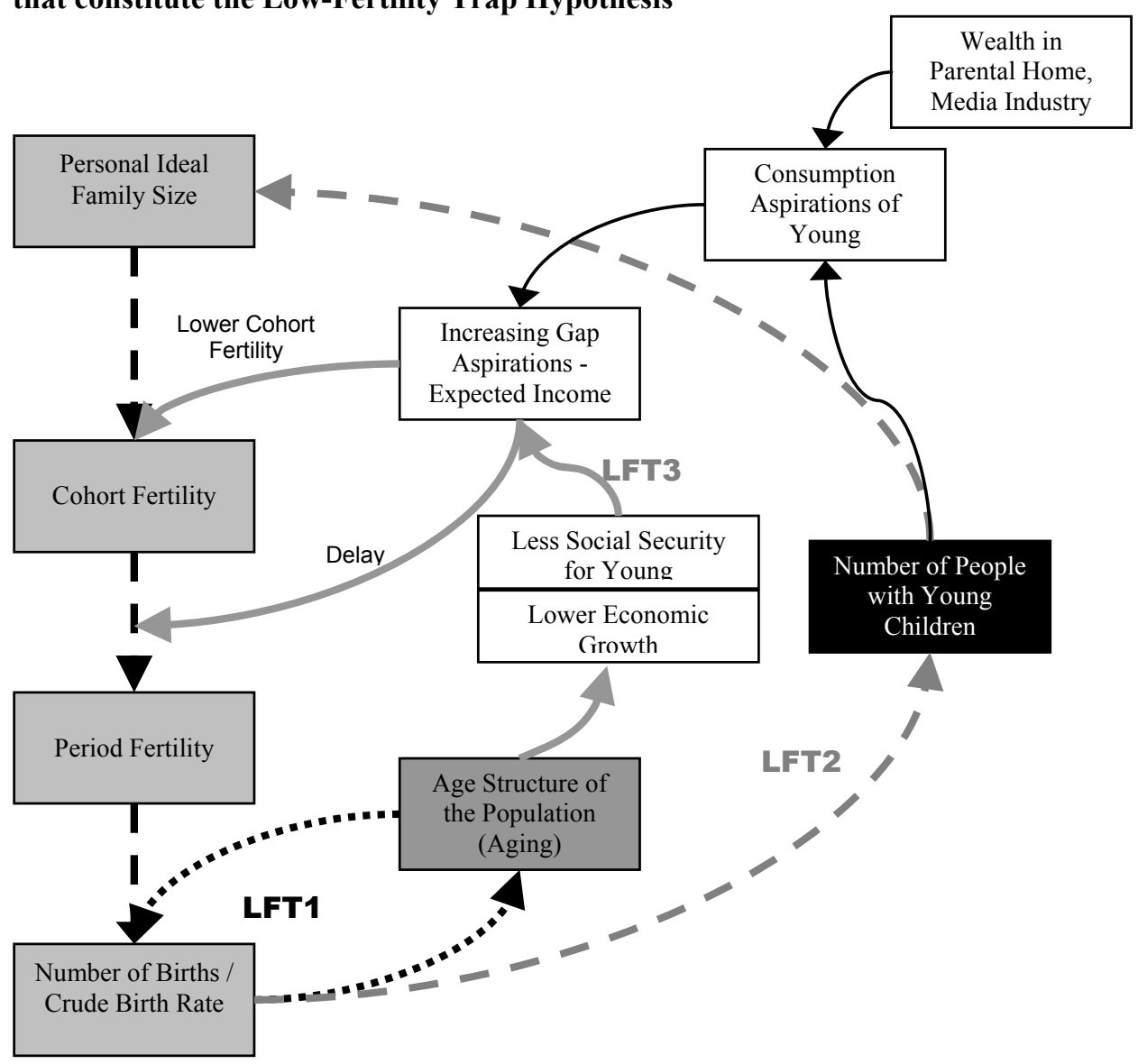

While the level of period fertility is determined by the rest of the model, the two dotted lines trace the feedback mechanism that is part of LFT-1: The number of births influences the age structure of the population and some three decades later, this modified age structure in turn determines how many births will result from a given level of period fertility. Of course the age structure can also be influenced by mortality and migration, but this is viewed as exogenous in LFTH. Instead of the absolute number of births, one may consider the crude birth rate (births divided by the total population size) as an output variable that lends itself better to international comparisons. But in the end, it is the number of births that counts in determining the age structure and, hence, all consequences of a changing age structure.

LFT-2 refers to a mechanism based on sociological reasoning. It is structured around the concept of personal ideal family size, which is assumed to be one of 
the factors determining actual cohort fertility. Personal ideal family size tends to be markedly higher than actual fertility, but it seems to be on the decline in several European countries (Goldstein et al. 2003). LFT-2 is based on the hypothesis that such a decline is triggered by declines in actual fertility that occurred some time ago. It is assumed that through the processes of socialisation and social learning, the social norms and in particular the family size ideals of the young generation are influenced by what people experience around themselves in term of families with young children. The fewer the children belonging to the environment that young people experience, the lower the number of children that will be part of their normative system in terms of what is a desirable life. Hence, in Chart 1, the feedback loop goes from the actual number of births in a population to the number of people with young children a few years later. This in turn is viewed as a key determinant of the personal ideal family size.

LFT-3 is based on an economic rationale referring to the gap between personal aspirations for consumption and expected income, which is assumed to result in fewer births. This argument is directly derived from Richard Easterlin's (1980) relative income hypothesis which claims that it is not the absolute (expected) income that matters, but rather income relative to aspirations that are largely formed in one's youth, and greatly dependent on the standard of living in the parental home. This first element of Easterlin's hypothesis has always been in the shadow of the second, far more controversial element, namely, that small cohort size will result in higher expected income. In our hypothesis, we will only refer to the first element, which is the less problematic one and has given the relative income hypothesis its name. In the more detailed discussion below, we will elaborate a bit on the second part, which does not seem to be a dominant force prevalent in Europe today.

In Chart 1, LFT-3 is represented by the solid lines. The gap between aspirations and expected income is a result of distinct changes affecting these two factors. As to expected income, a declining number of births is shaping the age distribution in a way that will result in more rapid ageing, which in turn triggers necessary changes in the current social security system, which typically means cuts that will mostly effect today's younger cohorts while being softer and more gradual for the older ones. In addition to this rather evident deterioration of expected social security benefits for the younger cohorts, rapid population ageing may also result in lower productivity and consequently in a globalised economy, lead to less investment and lower economic growth in the future. Both factors result in a more pessimistic economic outlook for today's younger generations, which is widely documented in opinion surveys. On the other hand, aspirations for material consumption are probably higher today than they ever were before. Today's youngsters are not only experiencing an unprecedented degree of exposure to advertising aimed at further raising the aspirations for consumption, but they also tend to come from relatively wealthy homes, their parents having fully benefited from the economic boom of the past decades. There is also a 
demographic factor: due to the fertility decline since the 1970 s, children have had to share parental wealth with fewer siblings, a factor that helped to raise the standard of living to which they have become accustomed.

In terms of the effect of this widening gap between aspirations and expected income (in the left column of Chart 1), we may assume two different effects on fertility. First and foremost, this declining, relative income would (according to Easterlin) affect the quantum of fertility, i.e., cohort fertility. But the extensive recent literature on the postponement of fertility and the resulting increase in the mean age of childbearing, which has an independent effect on depressing period fertility (the tempo effect), suggests that such a gap would also result in postponement. Young people are not yet certain how their future income will develop. Therefore, a likely reaction is to postpone the decision to have children until a later date when the future may seem clearer. Hence in Chart 1, we have two effects of declining relative income, one on the translation of personal ideals into actually wanted cohort fertility, and the other in the process of the timing of fertility, i.e., the translation of cohort into period fertility.

In the following sections there will be a more detailed discussion of the LFT-2 and LFT-3 mechanisms. Since LFT-1 has already been well studied and documented, it suffices to say that this simple consequence of the dynamics of age-structured populations implies that as a result of low fertility over the past years, fewer women (potential mothers) will be entering the reproductive age in the future. This exerts a significant downward pressure on the absolute number of births and the crude birth rate. It has been estimated that several countries and the EU as a whole have recently entered a period of negative population momentum, which technically is defined as an age structure implying future population shrinking, even if fertility should instantly increase to replacement level (keeping mortality constant and assuming no migration) (Lutz et al. 2003). With historically-given age structures, this negative momentum is an independent force toward fewer births in the future. The lower the fertility rate in the near-term future, the stronger the force of negative momentum in the longer-term future. While this demographic component of the LFT is purely an accounting effect at the aggregate level, the following two mechanisms relate to behavioural aspects.

\section{LFT-2: Declines in Ideal Family Size}

The second element of LFT relates to changes in ideal family size. It is based on an assumed reciprocal interaction between ideal and actual family size. Since this has already been discussed in other publications, we will only summarise the state of the discussion here and not present any new empirical data.

In demography there has been a long research tradition which is based on the assumption that actual fertility is influenced, at least to a certain degree, by fertility preferences. Several studies support this assumption (Barber and Axinn 
1998; Bankole 1995; Tan and Tey 1994). This is also reflected in the fact that several indicators of fertility preferences have become standard components of fertility surveys around the world for several decades. These indicators include societal ideal, personal ideal, desired family size, expected family size and others. Such indicators have also become an important basis for population policy rationales, particularly in developing countries where the main rationale of the Cairo 1994 ICPD rests on the observation that in many developing countries, desired family size is lower than actual fertility and hence policies should help couples to close this gap by meeting the unmet need for family planning, which in consequence would lead to lower fertility rates. In low-fertility countries, a gap exists in the other direction, with ideal family sizes as measured in surveys being typically higher than actual fertility rates. This offers policymakers in Europe a seemingly convenient policy rationale to try to help couples to actually have the (higher) family size that they would like to have in any case. But so far trying to close this gap in Europe has been a less successful endeavour than closing the opposite gap in a number of developing countries (Hagewen and Morgan 2005).

While it is a relatively clear argument that couples who do not have access to acceptable forms of contraception have more children than they want, and that making such services available will result in closing the gap, it is less clear what should be made available to couples that have fewer children than they say they want. In modern societies couples have several competing preferences; since they usually cannot meet all these wishes at the same time (some may even be mutually exclusive), they usually have fewer children than they say in surveys they would like to have (Demeny 2003). For this reason, stated family size ideals are also sometimes considered to be an upper bound for actual fertility (van Peer 2002).

But fertility preferences are not static; they tend to change over time and do so mostly in the direction of lower family size. In many (former) high-fertility countries, rapid declines in desired family sizes are well documented by the series of World Fertility Surveys and Demographic and Health Surveys (Cleland and Scott 1987; Westoff and Bankole 2002), and are assumed to be an important driver of the observed fertility declines. In the industrialised countries, measured ideal family sizes have been relatively stable (typically above replacement level) over the past decades, but there have been recent indications of a decline in some European countries (Goldstein et al. 2003). This is where LFT-2 comes into play and where it is assumed that after some years of stability, ideal family size may now enter a period of decline, particularly in those countries that recently experienced very low actual fertility rates.

There are good reasons to assume that preferences can be influenced by actual fertility. One can assume that young generations form their own family size ideals, like other norms and expectations, by looking at the actual childbearing behaviour of their parents or what they see as the family size of other influential people or in the environment around them. At this point we do not have to distinguish between 
influences on a person's ideal family size that are driven by the persons experience in his/her own family of origin and those driven by changes in the macro conditions around him/her. Actually, the possible influence from the family of origin would result in a more complex dynamics of change in the likely case that not all families have the same size, caused by the fact that the mean sibship size (family size from the children's perspective) is larger than mean family size (from the parent's perspective). Hence, here we will only consider the net effect (micro and macro level experiences) that the average level of fertility in a society has on the formation of family size ideals of young people.

As with many normative changes, there can be a significant time lag, which may explain why in many countries ideals still seem to be high, while at the same time actual period fertility is very low. A good example for such a lag in the change of family size norms can be found in the developing countries, where in the process of demographic transition, it often took several decades for fertility norms to change in reaction to mortality declines. But after such a lag, fertility norms have almost universally started to decline. The key question in this context is: Will fertility norms continue to decline or is there something that will keep them from falling below replacement level? With respect to actual fertility, for decades population forecasters have assumed that it would not fall below replacement only to find that already more than half of the world's population today is below replacement. Could this also happen to fertility ideals, particularly if one assumes that ideals are not independent from actual fertility? This follows the same logic as described by Rindfuss et al. (2004, p. 855) in the context of changing Japanese marriage behaviour: "Changes in attitudes likely create a feedback mechanism, influencing behaviour; and changes in behaviour likely create a feedback mechanism influencing attitudes." Here the argument would go as follows: Once the number of children (siblings, friends, children seen in other families, media) experienced during the process of socialisation falls below a certain level, one's own ideal family size would become lower, which in course may result in a further decline in actual family size and still lower ideals in the subsequent generation.

The idea that changes in fertility preferences may lag behind changes in actual reproductive behaviour is not new in the literature (Lee 1980). Recently, it has been taken as an explanation of the emergence of below-replacement family size ideals in Europe (Goldstein et al. 2003). After decades of a large predominance of the two-child norm in fertility preferences, in 2001 young women in the Germanspeaking countries reported an average ideal family size of 1.7 children (Goldstein et al. 2003). The authors explain such a decline by the drop of period fertility that in Germany and Austria occurred earlier than in other European countries. The German-speaking women showing sub-replacement family size ideals for the first time were born during the baby bust of the 1970s and have been socialised in smaller families. These females' generations would have taken 
the actual family size of their parents' generation, i.e., one or two children, as a standard for their own ideal family size.

Using a multilevel approach, Testa and Grilli (2006) give an empirical foundation to the assumption that changing fertility ideals lag behind the changes in actual reproductive behaviour, and interpret this relationship in an intergenerational micro-macro framework, where the context plays a major role. The authors showed that in those regional fertility contexts where the mean actual number of children of the old (parents') generations is lower, young individuals have a higher probability to prefer smaller families (Testa and Grilli 2006). In addition, the authors found that such a relationship is stronger in areas with below-replacement fertility levels, especially when fertility is below 1.5 children. Figure 2, taken from their analysis, plots the mean regional number of children born to the generation aged 40 to 60 versus the individual probability of preferring a given family size of young individuals aged 20 to 39 coming from the estimates of the multilevel model used by Testa and Grilli (2006). Although the figure has to be interpreted in a cross-section framework - the data come from one cross-sectional survey and simply reflect the regional differences - the picture can shed some light on the reasons why the two-child norm has been so stable in the last few years: only at very low levels of actual fertility, the two-child norm starts to decrease and the ideal one-child family becomes more and more likely.

According to the authors, one of the possible mechanisms responsible for the relationship between contextual childbearing features and individual behaviour may be the social learning process between young and old that does not necessarily have to go through the children-parent relationship, although the family context may take a very important role (Axinn et al. 1994; Murphy 1999; Fernández and Fogli 2005). However, further analysis would be needed to investigate which mechanism lies behind the intergenerational transmission of ideal family size.

The analysis by Testa and Grilli (2006) may provide an answer to a possible key criticism of such a hypothesis of a downward spiral of actual and ideal family size, namely, that declining fertility already experienced in the previous decades has not yet been accompanied by generally decreasing fertility ideals. An exciting new test of this hypothesis will be possible when the data from the Eurobarometer 2006 , which has questions on ideal family size identical to that of 2001 , become available. 
Figure 2:

Effect of the mean number of children ever born among older generations on the younger generations' individual probability of a given ideal family size. All respondents were aged 20 to 39 and desired at least one child. EU-15, 2001

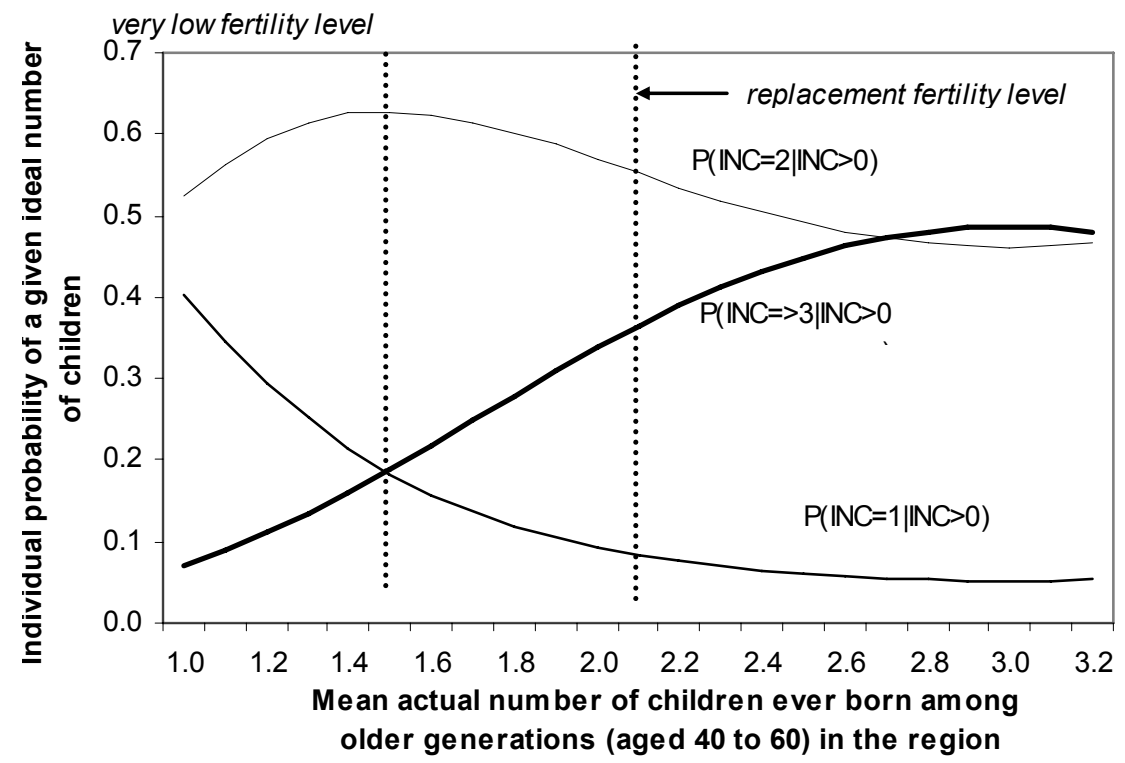

Source: Testa and Grilli (2006).

Note: $\mathrm{INC}=$ ideal number of children. The two vertical lines denote the replacement fertility level $(2.1 \mathrm{children})$ and the very low fertility level fixed at 1.5 children.

\section{LFT-3: The Relative Income Argument}

\subsection{Easterlin's reasoning}

The main reasoning for this part of the low-fertility trap hypothesis is directly taken from Richard Easterlin's (1980) relative income hypothesis. In a section on the determinants of fertility, Easterlin writes:

I believe that an important factor affecting a young couple's willingness to marry and to have children is their outlook for supporting their material aspirations. If the couple's potential earning power is high in relation to aspirations, they will have an optimistic outlook and will feel freer to marry and have children. If their outlook is poor relative to aspirations, the couple will feel pessimistic and, consequently, will be hesitant to marry and have children. ... Note that two elements enter into the judgment about the couple's economic prospects. One is their potential earning power; the other is their material aspirations. (Easterlin 1980, p. 39) 
These two factors described by Easterlin also form the basis of the LFT-3 mechanism as described in Chart 1 . Both the level of cohort fertility and the timing of fertility are assumed to be influenced by the ratio of expected income to aspirations.

Easterlin defines quite precisely what he means by material aspirations, which he views as the lifestyle learned in the family or origin:

By life-style, I mean how the material standards of young adults are formed - why one generation, say, views a car as a luxury and the next, a necessity. My argument is that the material expectations of young adults are largely the unconscious product of the environment in which they grow up. ... And this environment is very largely shaped by the economic circumstances, or income, of one's parents. (Easterlin 1980, p. 40-41)

Easterlin then proposes to use the income of the father as a proxy for the level of aspirations and the income of the young man as a proxy for expected income. The ratio of these two income measures of younger workers to older workers should then provide a quantitative proxy for relative income. If the ratio increases, then relative income increases and fertility will be higher; if it decreases, then fertility can be expected to decline. Easterlin showed that this can offer a plausible explanation of the US baby boom followed by a fertility decline.

How relevant is this relative income argument for Europe today? Can it provide guidance for making assumptions about the future of fertility? In the following we will present some empirical evidence showing that indeed in many parts of Europe, relative income seems to be on the decline, and there are no convincing reasons to dismiss the argument put forward by Easterlin that indeed this should be a factor in determining future fertility declines. To avoid confusion, it is important to stress at this point that we do not refer to the second part of Easterlin's hypothesis, namely, the assumption that smaller cohorts will have higher incomes. This assumption seems much more problematic in the European context and will be discussed briefly at the end of this section. Our reasoning here refers exclusively to the relative income argument as described above.

Figure 3 plots the relative income measure proposed by Easterlin for four selected countries for which age-specific income data are available from the last decades. Ideally, the income data for the parents should refer to the period during which the young generation experienced its socialisation, and should be adjusted for changes in purchasing power. Since the necessary data are difficult to find, Easterlin (1980) uses only the father's income lagged by five years. Here, as a first approximation, we compare the incomes of the two age groups in the same period. The ratio plotted in Figure 3 is the income of economically active men aged 25-34, which refers to the fathering children, divided by the income of economically active men aged 45-54, which is supposed to capture the income of the parental generation. This ratio should be above 1.0 if young people give expected incomes higher than their aspirations, which according to Easterlin 
should result in higher fertility. Any value below 1.0 shows that expected income falls short of aspirations and should result in a fertility depressing effect. The figure clearly shows that all values are significantly below 1.0 for the four countries studied. The ratio is lowest in Japan, and somewhat higher in Sweden, Italy and the UK. Based only on these data that show a decline in relative income from the 1970s to the 1990s, one would have expected fertility to decline during the 1970s for Japan, Sweden and the United Kingdom and the 1980s for Italy. This fits very well with actually observed fertility trends in these countries. But what is also visible from the graph is that relative income does not show a cyclical pattern but rather exhibits a continuous decline. This is in sharp contrast to the expectation that Easterlin based on the second part of his hypothesis, namely, that relative income would increase for the smaller cohorts entering the labour market. This led him to expect a new baby boom for the 1990s. But in all four countries, the young cohorts aged 25-34 in 1991-2000 had an even lower relative income than the same age groups 20 years earlier. In light of these trends in relative income, the continued low fertility in the 1990s comes as no surprise.

What does this imply for the future? Can we expect that the trend in relative income will reverse itself in the near future and that young adults will have higher incomes than what they see with their parents? Probably not. One can, of course, doubt that the chosen measure of relative income that compares two age groups at one point in time gives a good approximation of the relationship between the two factors aspirations and expected income. For this reason, in the following we will review some broader evidence and data on the two variables that enter the relative income argument, and find out if we have reason to assume certain trends in the future.

Figure 3:

Relative income (income of full-time workers aged 25-34 divided by the income of active persons aged 45-54) since the 1970s for four countries where data are available

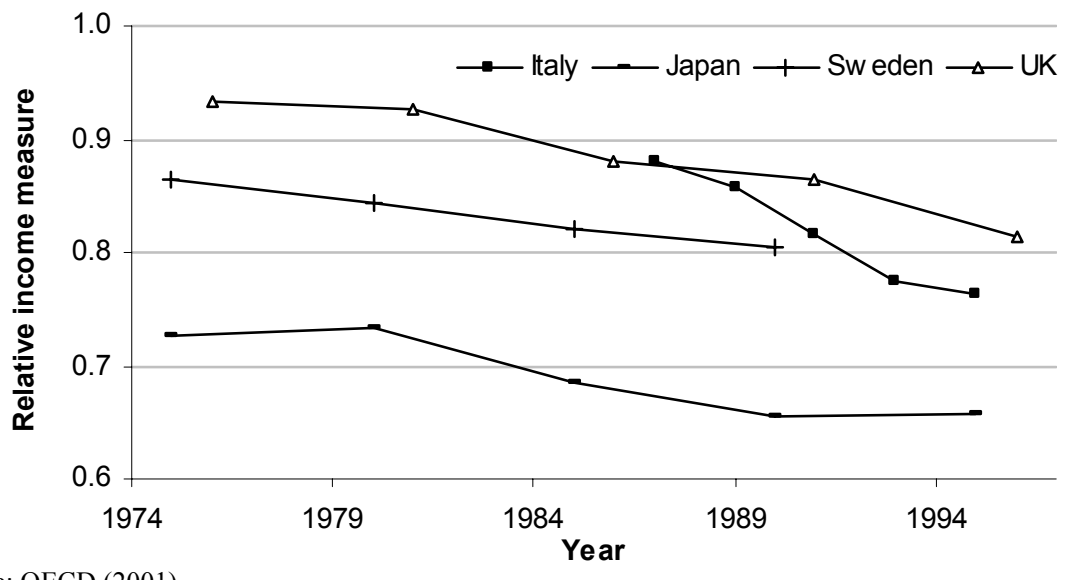

Source: OECD (2001). 


\subsection{Economic Aspirations}

Even if it is very hard to predict how the (absolute) income of younger people will develop in Europe in the future, it seems fair to say that the general aspirations from material consumption have been on the rise for quite some time and are unlikely to decline soon. This may be due in part to increasing wealth in parental homes, and to a penetrating advertising industry in which increasing material consumption, especially of certain expensive brands, is portrayed as the only avenue to satisfaction and happiness. Several youth surveys show that young people seem to be particularly open to this kind of enhancement to consumption aspiration. Given this apparently strong increase in aspirations and a more modest increase (or even decline) in the purchasing power of younger workers, personal satisfaction with the level of consumption will possibly never be reached. Advertisers no longer simply tell people about a product and how it would improve the purchaser's life, but they sell a lifestyle, an image, an easy-to-achieve identity that could be made one's own. One might argue that consumption ideals are likely to be set higher (but not unattainably higher) than what individuals currently consume, in order to maximise sales and profits. If this is true, this implies that the match between aspirations and expected purchasing power for the broad segments of the population will continue to be unfavourable.

Statistics Norway (2005) shows that annual per-person consumption increased from slightly above 60,000 to around 150,000 NOK from 1970 to 2003 (year 2000 prices). Iacoviello (2005) states that US household debt, having been relatively stable throughout the 1960s and 1970s, has jumped out of proportion since the 1980s, with real activity rising between 1981 and 2003 from 67 per cent to 113 per cent of disposable personal income. Increases in household debt as compared to disposable income have occurred in most countries where data are available, and even stronger increases than in the US took place in the Netherlands, Denmark and Australia (Debelle 2004).

Stutzer (2004) shows that as people get richer, their material aspirations increase. Consistent with processes of adaptation and social comparison, income aspirations increase with people's income as well as with the average income in the community they live in. Furthermore, Stutzer's analysis shows that higher consumption aspirations decrease wellbeing.

\subsection{Declining Relative Wellbeing of the Young}

In Sweden, studies show that the feeling of insecurity has increased for the younger age groups as relative living standards for them have decreased over time from 1980-2003 (Blossfeld et al. 2005; Vogel and Råbäck 2004; SCB 2005). While the unemployment level in peak childbearing ages (25-29 year olds) was 1-4 per cent from 1970-1991, it fluctuated between 5-14 per cent in the period 
1992-2003. While in 1986 only 14 per cent had temporary work contracts, by 200325 per cent did. During the same period, the share who reported having stressful work in the age group 25-29 increased from 7 per cent to 13 per cent.

Vogel and Råbäck (2004) also find that health disadvantages may have have increased more for younger age groups than for older ones. The percentage with reported health problems increased from 7 per cent to 10 per cent for the 20-24 year olds, while it decreased from 41 per cent to 36 per cent for the 60-64 year olds. Likewise, a loss of trust and interest in politics seems more evident since the share of 22-29 year olds who took part in elections decreased from 86 per cent to 73 per cent between 1970 and 2002, while the voting share of 65-74 year olds decreased by only about half as much, from 91 per cent to 84 per cent. Young people have also disproportionately become victims of crime: 15 per cent of 2024 year olds were exposed to crime in 2003, while it was only 10 per cent in 1980. Meanwhile, the rate of suffering from a crime was stable at around 2 per cent for 65-69 year olds. Individuals in their 20 s were less likely to have access to cars in 2003 than in 1980. Likewise, the available living space has gotten tighter for the younger people and larger for the older. Between 1980 and 2003, the number of individuals per 100 rooms increased from 59 to 65 for 20-24 year olds, while it decreased from 41 to 34 for the 60-64 year olds.

In comparison with other group inequalities, generational inequality is expanding in relation to others. Joachim Voegel and Lars Häll write: "Statistics Sweden's surveys and previous reports show that, among other things, class and gender differences have been reduced in the long term, while generation differences have increased as far back as we can follow in the statistics." (SCB 2005, p. 111) Unfortunately, for many other European countries, no comparable studies about the relative wellbeing of younger people versus older ones seem to exist. One might expect that particularly in the southern European countries, this trend of declining relative wellbeing for the younger generation is even more pronounced. If the available youth unemployment rates are taken as an indicator, there is now doubt about this. While youth unemployment rates in 2001 were 12 per cent in Sweden and only 4 per cent in the Netherlands, they were 21 per cent in Spain, 27 per cent in Italy and 28 per cent in Greece. 71 per cent of all EU citizens aged 20-24 fear the transfer of jobs from their countries (Eurobarometer 2005). Combined with high aspirations for consumption, this is likely to result in a miserable relative income for the young.

LFT-3 assumes that such declining relative income is not only the result of exogenous trends, but can in part be seen as a consequence of lower fertility in the past and the resulting population ageing. There are two possible effects, one at the household level and one at the macro level. The first effect tends to increase the aspirations through declining family size, i.e., youngsters today on average have to share the parental wealth with fewer siblings and hence, experience a higher standard of living in their childhood. The other mechanism operates at the societal level, where governments have to reform the social security system as a 
consequence of population ageing, which almost universally tends to result in the hardest cut for the younger generations. Almost all pension reforms and early retirement schemes are phased in slowly, giving those still working in their 50s (who tend to represent the majority among politicians and trade union officials who negotiate the deals) the opportunity to still benefit from the generous old systems while transferring the full impact on the younger age groups. Even reforms of the labour market, which have to do away with old privileges, are sometimes restricted to the younger ones. One only has to think of the recent discussions in France about a law liberalising the labour market that would have affected only people below the age of 26, or recent pension reforms in Germany and Norway that have made pension systems less generous mainly for younger generations. In this light it does not surprise us that an increasing number of youths in Europe has a pessimistic outlook for the future.

Another key factor is the price of housing, which increasingly tends to present a barrier to home establishment of young couples who are in principle willing to start their own family. This cost factor has risen substantially over the last decades. In most EU countries, housing prices have outstripped increases in average disposable income (ECB 2003). The impact of this development will probably be most detrimental on the young, who have less disposable income and are less likely to own a home as compared to other age groups (OECD 1998).

\subsection{Effect of Relative Cohort Size}

As mentioned above, in the second part of his relative income hypothesis, Easterlin argues that smaller cohort sizes will improve labour market prospects for the young and lead to higher relative income. Since most people do not distinguish the second part of Easterlin's hypothesis from the first, which is the one that we focus on, we should briefly discuss the issue in order to avoid confusion. A brief - though in this context clearly non-exhaustive-discussion makes sense because this second part could be seen as an argument for expecting a recovery of relative income and, therefore, a recovery of fertility in Europe over the coming years, when smaller cohorts enter the labour market.

For the U.S., Easterlin (1980) finds that in the 1950s, there were few new labour market entrants and at the same time good labour market prospects, while in the 1970s, there were many new labour market entrants and poor labour market prospects. He argues that the inverse association between cohort size and labour market opportunities is causal, which is why the assumption of a negative relationship between cohort size and aggregate labour market outcomes is often termed the "Easterlin hypothesis."

Studies supporting this assumption, at least in one direction in terms of larger cohort sizes having a negative effect on their incomes, include Korenman and Neumark (2000). Using a sample of OECD countries, they find that there is a 
weak increase in youth unemployment rates when larger cohorts enter the labour market. Martin and Ogawa (1988) consider the Japanese case and find that the wage ratios of 20-29 to 40-49 year olds in Japan is reduced by 1 per cent when the share of the former increases by 10 per cent. Similar findings using American data are provided by Gordon (1982) and Shimer (1998). However, at least for the US, the idea that the reason for decreasing wages of the young in the 1980s was their large cohort size was largely abandoned when the wages of the young did not rebound after the baby bust entered the labour market (Gottschalk 2001).

Jimeno and Rodriguez-Palenzuela (2002) analyse OECD data and find that the relation between cohort size and unemployment is evident mostly when labour markets are rigid. If such effects of cohort size exist, they are mostly temporal, disappearing when labour markets have adjusted to changes in the labour supply. When labour markets are flexible, larger cohorts integrate into the labour market more easily. Also, the possible presence of such an effect of larger cohort size leading to worse conditions for the members of that cohort does not necessarily imply that the reverse will be true and smaller cohort size will lead to improved conditions.

Evidence on age and entrepeneurship even suggests the possibility of an effect that goes opposite to the direction proposed by Easterlin. A survey of 34 countries finds that fewer young people means fewer start-ups of new enterprises and fewer jobs, as peak entrepreneurial activity typically takes place in the young ages $25-44$, which may imply that population ageing could cause less job creation (Global Entrepreneurship Monitor 2004). Hence, belonging to small cohorts may even negatively affect overall labour market conditions, and smaller cohorts could mean fewer start-ups of new enterprises and fewer jobs.

Shimer (2001) analyses evidence for spatial units in the U.S. These more disaggregated data suggest that smaller cohort sizes tend to lead to worse employment and labour market conditions. Smaller youth cohorts in a region are associated with lower labour force participation rates and increased unemployment levels. Shimer argues that this is because firms tend to relocate away from where labour supply is expected to decrease, and information on cohort sizes of future labour market entrants are easily available. Following Shimer's regional data approach for Sweden, using data from 1985-1999, Skans (2005) also finds evidence that young workers are negatively affected by belonging to a small cohort.

This short discussion of some recent empirical evidence and studies focusing on the role of cohort size referring to the second part of Easterlin's hypothesis can by no means be seen as an exhaustive discussion of the issue. It only sheds some doubts on the widely held expectation that somehow a smaller cohort size will automatically result in higher income for the members of such smaller cohorts. Market rigidities and several other factors discussed above may indeed make it worse for members of smaller cohorts. This would be more in line with the reasoning of Preston (1984) in his PAA presidential address, where he argued that 
the power and the money tend to go where the large cohorts are. This factor is reinforced by our democratic systems in which the young under 18 years of age cannot cast a vote and where the elderly tend to have much better organised lobbies.

\section{Conclusions and Discussion}

As mentioned in the introduction, this contribution is meant to stimulate the informed and science-based discussion about the future of fertility. It does not wish to say that very low fertility countries are already trapped in a downward spiral of lower fertility. It only wishes to point out this possibility as something that should be taken into serious consideration.

The future level of fertility in Europe, and in particular in the very low fertility countries, is an important issue. Many of the analyses about the consequences of ageing that are being discussed by the economic and finance ministers of Europe among others, are based on the Eurostat projections which assume an end to the fertility decline. Should fertility continue to decline, then all the consequences of population ageing will be more dramatic than currently assumed.

But there is an even more immediate political dimension which may add some urgency to the question of whether governments should get actively involved in trying to raise the level of period fertility. Should the dynamic and selfreinforcing mechanisms assumed to be at work under this hypothesis indeed become a dominating force in determining the future level of fertility, then possible action to counteract this trend will have a far greater chance of succeeding if it is implemented soon. Once the assumed demographic regime change is far enough advanced, it may be very difficult, if not impossible, to reverse. Once the ideal family size of the young generation has begun to decline and fall well below replacement, as seems to be happening currently in the German-speaking countries, then it may be too late for a reversal of this trend. In this respect, particularly the central and eastern European countries that used to have fertility not so far from replacement level until the transition around 1990, and still have high family size ideals today despite a precipitous decline in period fertility, seem to be in a critical stage that might still be influenced by policies. If period fertility in these countries should increase in the near future-possibly through policies affecting the tempo of fertility rather than cohort fertility-this may still help to stop the "tanker" of changing family size norms from making a full turn. Through such immediate action, an irreversible demographic regime change might still be stopped by making children a part of normal life again. This will enhance the chance that in the future, young people will have their norms shaped in such a way that they still see children as part of the life they wish to live, as seems to be the case in France and the Nordic countries. A similar chance may 
still exist in the Mediterranean countries, where period fertility declined later than in the German-speaking countries and where the ideals still seem to be rather high on average, at least up to 2001 .

In other words, if we assume the LFTH to be true, then any attempt to stop a demographic regime change in the very low fertility countries is of high urgency and some of the measures recommended by McDonald (2006, this volume) should be implemented by governments with priority and determination. In this context the conventional linear thinking in terms of gradual and reversible fertility trends leading to gradual changes in its consequences should be abandoned and replaced by a systems thinking aproach including the possibility of non-linear responses and positive feedback loops including tipping points and irreversible regime changes.

In the case where the mechanisms assumed under the LFTH are not at work and the LFTH can be falsified, governments can be more relaxed about the fertility trends and take the "wait and see" approach that Van de Kaa (2006, this volume) recommends. Hence, the evaluation of the LFTH is of critical political importance.

How can we be better informed about the likelihood that such a possible selfreinforcing mechanism toward ever-declining birth rates will actually be at work? First, more must be done in specifying possible counterarguments and counterhypotheses. This has not been done here because the specific point of this paper is to introduce the hypothesis itself. It is now up to the scholarly discussion to define and test counterarguments. Based on the discussion in Lutz (2006) it seems that the two main avenues of counter argumentation would be (a) the view that there is some rock bottom level of fertility which is caused by some feature of human nature that would always ensure a certain minimum level of reproduction. However, since this does not seem to be the case at individual level as shown by the given prevalence of childlessness, the argumentation needs to focus on the societal level, assuming certain average levels of fertility or maximum proportions of childless persons, i.e., something that has to do with the nature of human societies rather than the individual disposition. A second frequently heard argument is that (b) governments would not tolerate a situation of extremely low fertility because of the serious aggregate level consequences and would radically change the incentive structures until it would be a rational choice to have more children than originally considered ideal. To assess how realistic such policies would be both in terms of being accepted by the majority of the population and then actually having a sizeable impact on fertility goes far beyond the scope of this paper.

Another field where more work needs to be done is in collecting more empirical data with this specific research question in mind. Clearly much more data needs to be analysed and collected for being able to comprehensively test this hypothesis. Particularly in the field of relative income, our search of the literature resulted in a very scattered and unstructured picture about the trends in aspirations 
and expected income in different parts of Europe. Since relevant data are only collected and studies only conducted when there is a specific research agenda on the table, we herewith want to put the hypothesis on the table and hope that it will inspire more data collection and analyses in the near future.

\section{References}

Axinn, W. G., M. E. Clarkberg, and A. Thornton. 1994. "Family influences on family size preferences." Demography 31(1): 65-79.

Bankole A. 1995. "Desired fertility and fertility among the Yoruba of Nigeria: a study of couple preferences and subsequent fertility." Population Studies 49(2): 317-328.

Barber, J. and W. G. Axinn 1998. "The impact of parental pressure for grandchildren on young people's entry into cohabitation and marriage." Population Studies 52(2): 129144.

Blossfeld, H.-P., E. Klijzing, M. Mills and K. Kurz (eds.) 2005. Globalization, Uncertainty and Youth in Society. London/New York: Routledge.

Bucht, B. 1996. "Mortality trends in developing countries: A survey." In: W. Lutz (ed.) The Future Population of the World. What Can We Assume Today? Revised Edition. London: Earthscan, pp. 133-148.

Cleland, J. and C. Scott. 1987. The World Fertility Survey - An Assessment. London: Oxford University Press.

Debelle, G. 2004. "Macroeconomic Implications of Rising Household Debt." BIS Working Papers 153. Basel, Switzerland: Bank for International Settlements.

Demeny, P. 2003. "Population policy dilemmas in Europe at the dawn of the twenty-first century." Population and Development Review 29: 1-28.

Easterlin, R. A. 1980. Birth and Fortune: The Impact of Numbers on Personal Welfare. New York: Basic Books.

ECB. 2003. "Structural factors in the EU housing market." Report. Frankfurt, Germany: European Central Bank.

Eurobarometer. 2005. "'Youth takes the floor.' Young Europeans' concerns and expectations as to the development of the European Union" Background note based on relevant findings from Eurobarometer Data.

«http://ec.europa.eu/public_opinion/archives/notes/back_note_en.pdf»

Eurostat. 2005. New Cronos Database. Theme 3: Population and Social Conditions. «http://epp.eurostat.cec.eu.int/portal/page?_pageid=1996, $45323734 \&$ dad=portal\&_schema=PORTAL\&screen=welcomeref\&open=/Popula/pr oj\&language $=$ en\&product $=E E_{-}$MASTER_population\&root=EU_MASTER_populati on\&scrollto $=0$ »)

Fernández, R. and A. Fogli. 2005. "Fertility: The role of culture and family experience." NBER Working Paper 11569. Cambridge, MA: National Bureau of Economic Research.

Global Entrepreneurship Monitor. 2004. National Team Reports. «http://www.gemconsortium.org/»

Goldstein, J., W. Lutz, and M. R. Testa. 2003. "The emergence of sub-replacement family size ideals in Europe." Population Research and Policy Review 22(5-6): 479-496. 
Gordon, R. 1982. "Inflation, flexible exchange rates, and the natural rate of unemployment." In: M. Baily (ed.) Workers, Jobs and Inflation. Washington, D.C.: Brookings Institution, pp. 89-152.

Gottschalk, P. 2001. "What can we learn from the cohort size literature about the future demand for the greying baby boomers?" Manuscript, Roundtable on the Demand for Older Workers, The Brookings Institution, «Www.bc.edu/centers/crr/special_pubs/gottschalk_ld.pdf»

Hagewen, K. K. and P. S. Morgan. 2005. "Intended and ideal family size in the United States, 1970-2002." Population and Development Review 31(3): 507-527.

Iacoviello, M. 2005. "Household Debt and Income Inequality, 1963-2003." Mimeo. Boston, MA: Boston College.

Jimeno, J. and D. Rodriguez-Palenzuela. 2002. "Youth unemployment in the OECD: demographic shifts, labour market institutions, and macroeconomic shocks." $E C B$ Working Paper 155. Frankfurt, Germany: European Central Bank.

Korenman, S. and D. Neumark. 2000. "Cohort crowding and youth labor markets: A cross-national analysis." In: D. G. Blanchflower and R. B. Freeman (eds.) Youth Employment and Joblessness in Advanced Countries. National Bureau of Economic Research - Comparative Labor Markets Series. Chicago: Chicago University Press, pp. 57-106.

Lee, R. 1980. "Aiming at a moving target: Period fertility and changing reproductive goals." Population Studies 34: 205-226.

Lutz, W. 2006. "Alternative paths for future European fertility: Will the birth rate recover or continue to decline?" In: W. Lutz, R. Richter, and C. Wilson (eds.) The New Generations of Europeans. Demography and Families in the Enlarged European Union. London: Earthscan.

Lutz, W. and V. Skirbekk. 2005. "Policies addressing the tempo effect in low-fertility countries." Population and Development Review 31(4): 699-720.

Lutz, W., B. C. O’Neill, and S. Scherbov. 2003. "Europe's population at a turning point." Science 299: 1991-1992

Martin, L. G. and N. Ogawa. 1988. "The effect of cohort size on relative wages in Japan." In: R. D. Lee, W. B. Arthur, and G. Rodgers (eds.) Economics of Changing Age Distributions in Developed Countries. London: Oxford University Press, pp. 59-75.

McDonald, P. 2006. "An assessment of policies that support having children from the perspectives of equity, efficiency and efficacy." Vienna Yearbook of Population Research 2006: 213-234.

McDonald, P. 2005. "Low Fertility in Singapore: Causes, Consequences and Policies." Paper presented at the Forum on Population and Development in East Asia, Beijing, May 16-17, 2005.

Murphy, M. 1999. "Is the relationship between parents and children really weak?" Social Biology 46(1-2): 122-145.

OECD. 1998. "Work force ageing in OECD countries." In: OECD Employment Outlook. Paris: Organisation for Economic Co-operation and Development, pp. 123-150.

OECD. 2001. "Labor Market Statistics.” CD-Rom. Paris: Organisation for Economic Cooperation and Development.

Oeppen, J. and J. Vaupel. 2002. "Broken limits to life expectancy." Science 296: 10291031.

PRB. 2005. "World Population Data Sheet of the Population Reference Bureau." Washington, D.C. «www.prb.org» 
Preston, S. H. 1984. "Children and the elderly: Divergent paths for America's dependents." Demography 21(4): 435-457.

Rindfuss, R., M. K. Choe, L. L. Bumpass, and N. O. Tsuya. 2004. "Social networks and family change in Japan." American Sociological Review 69(6): 838-861.

SCB (Statistiska Centralbyrån). 2005. Young Adults in Swedish Society. Levnadsförhållanden Report 108. Stockholm: Statistics Sweden.

Shimer, R. 2001. "The impact of young workers on the aggregate labor market." Quarterly Journal of Economics 116: 969-1007.

Shimer, R. 1998. "Why is the US unemployment rate so much lower?" NBER Macroeconomic Journal, Vol. 13. Cambridge, MA: National Bureau of Economic Research.

Skans, O. N. 2005. "Age effects in Swedish local labor markets." Economics Letters 86(3): 419-426.

Statistics Norway. 2005. “Årlig nasjonalregnskap fra 1970 til 2004” [Annual National Accounts 1970 to 2004]. Available at «www.ssb.no/nr» Website accessed 21.12.05.

Stutzer, A. 2004. "The role of income aspirations in individual happiness." Journal of Economic Behavior and Organization 54(1): 89-109.

Tan P. C. and N. P. Tey. 1994. "Do fertility intentions predict subsequent behavior? Evidence from Peninsular Malaysia." Studies in Family Planning 25(4): 222-231.

Testa, M. R. and L. Grilli. 2006. "The influence of childbearing regional contexts on ideal family size in Europe: A multilevel analysis." Forthcoming in Population.

UN. 2005. World Population Prospects. The 2004 Revision. New York: United Nations, Department of Economic and Social Affairs, Population Division.

UN. 2004. World Population to 2300. New York: United Nations, Department of Economic and Social Affairs, Population Division.

UN. 1999. World Population Prospects. The 1998 Revision. New York: United Nations, Department of Economic and Social Affairs, Population Division.

Van de Kaa, D. 2006. "temporarily new: on low fertility and the prospect of pro-natal policies." Vienna Yearbook of Population Research 2006: 193-211.

Van Peer, C. 2002. "Desired and achieved fertility." In: E. Klijzing and M.Corijn (eds.) Dynamics of Fertility and Partnership in Europe: Insights and Lessons from Comparative Research, Vol. 2. New York and Geneva: United Nations, pp. 117-141.

Vogel, J. and G. Råbäck. 2004. Materiell ojämlikhet i tids- och internationellt perspektiv. (Material inequality over time and across countries). Chapter 4 in Levnadsförhållanden Report 100. Stockholm: Statistics Sweden.

Westoff, C. and A. Bankole. 2002. "Reproductive Preferences in Developing Countries at the Turn of the Century." Comparative Reports (CR) 2. Calverton, USA: Demographic and Health Surveys.

Wilson, C. 2004. "Fertility below replacement level.” Science 5668: 207-209. 